bioRxiv preprint doi: https://doi.org/10.1101/781138; this version posted September 24, 2019. The copyright holder for this preprint (which was

not certified by peer review) is the author/funder, who has granted bioRxiv a license to display the preprint in perpetuity. It is made available under aCC-BY 4.0 International license.

\title{
Radiofrequency Remote Control of Thermolysin Activity
}

Christian B. Collins

Department of Chemistry

Campus Delivery 1872

Colorado State Unviersity

Fort Collins, CO 80523-1827

Christian.B.Collins@gmail.com

Corresponding Author:

Christopher J. Ackerson

Department of Chemistry

Campus Delivery 1872

Colorado State Unviersity

Fort Collins, CO 80523-1827

ackerson@colostate.edu 


\title{
Radiofrequency Remote Control of Thermolysin Activity
}

\author{
Christian B. Collins and Christopher J. Ackerson*
}

\begin{abstract}
Nearly all biological processes are regulated by enzymes, precise control over specific enzymes could create the potential for controlling cellular processes remotely. We have successfully shown that the thermophilic enzyme thermolysin can be remotely activated in $17.76 \mathrm{MHz}$ radiofrequency (RF) fields when covalently attached to $6.1 \mathrm{~nm}$ gold coated magnetite nanoparticles. Without raising the bulk solution temperature, we observe enzyme activity as if the solution was $16 \pm 2{ }^{\circ} \mathrm{C}$ warmer in RF fields, or an increase in enzymatic rate of $129 \pm 8 \%$. Kinetics studies show that the activity increase of the enzyme is consistent with the induced fit of a hot enzyme with cold substrate.
\end{abstract}

\section{Introduction}

The use of temperature changes to modulate biological processes is ubiquitous. Well known examples include cooking to neutralize foodborne pathogens, the polymerase chain reaction (PCR) [1-5], thermal cancer treatment [6-10], and thermal deactivation of enzymes (e.g., restriction endonucleases) [11-13]. These processes all rely on bulk(macro)-scale heating.

The routine use of thermal manipulation of biological processes is 'bulk heating' - heating the entire sample. However, the possibility of heating discrete and defined local regions within a sample offers the potential to extend the paradigm of thermal manipulation of biological samples to allow targeting of discrete molecules with minimal collateral heating.

The advent of nanoparticles that convert external stimuli to heat gives rise to the possibility that thermal modulation of biological processes could be spatially targeted with high resolution. Indeed, inorganic particles that heat upon thermal stimuli have been used to modulate biological activity. Gold nanoparticles conjugated to DNA can thermally modulate DNA hybridization [14]. Micron-sized ferromagnetic iron-oxides can thermally control the activity of amylase under $0.34 \mathrm{MHz}$ RF irradiation [15]. Dehalogenase enzymes immobilized in a gel matrix with iron-oxide particles of unknown size could be thermally controlled using the nanoparticles to heat the entire hydrogel [16]. Gold nanorods that heat upon NIR, $800 \mathrm{~nm}$ laser stimulation can modulate the activity of glucokinase [17].

Prior examples of particle mediated influence of enzyme activity are done with particles of widely varying size, from micron sized iron-oxides to $30 \times 10 \mathrm{~nm}$ nanorod [17]. The different sizes of particle imply different spatial resolutions to which heat can be delivered. For instance, micron [18] and 100+ nm sized particles [19] could be effective at cellular resolution-heating nearby cells but not far away cells, while sub-10 nm sized particles may heat at molecular resolution-heating nearby molecules but not far-away molecules. We choose to utilize smaller particles than previously reported, in this sub-10 $\mathrm{nm}$ size regime $(6.1 \mathrm{~nm})$ to improve heat resolution and increase the surface area to volume ratio, allowing for increased area for heating targets and heat transfer. Figure S1 summarizes the differences in surface area to volume ratio and shows the striking difference for a fixed volume fraction of particles.

Herein, we demonstrate the first thermal manipulation of enzymatic activity by 'hot' nanoparticles at molecular resolution. We use $6.1 \mathrm{~nm}$ gold coated magnetite particles covalently linked to the thermostable protease, thermolysin. The superparamagnetic $4.5 \mathrm{~nm}$ magnetite cores heat under radiofrequency (RF) irradiation at $17.76 \mathrm{MHz}$, as the magnetic field torques the magnetic moments and the particles relax via Neel relaxation mechanisms [20-24]. 


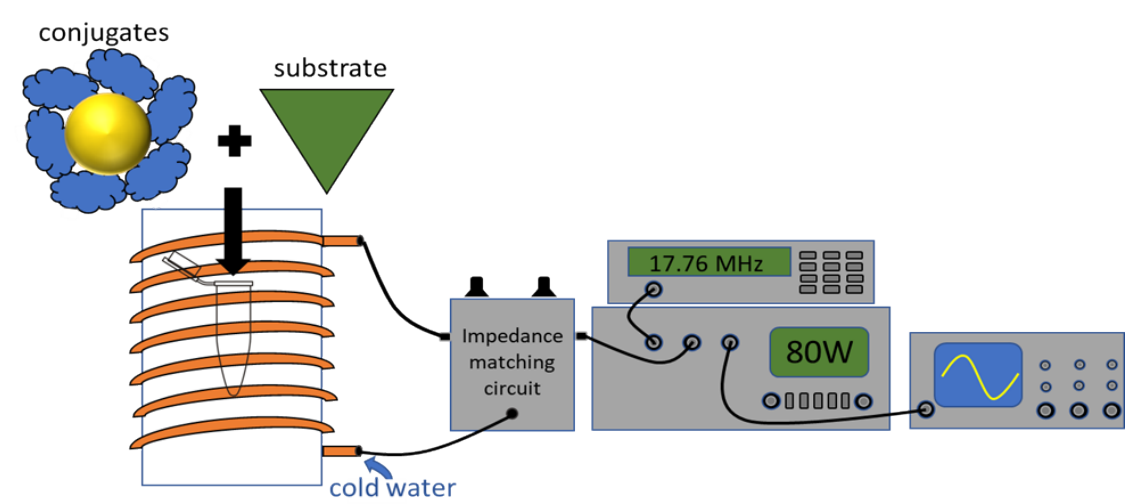

Figure 1. Illustration of radiofrequency heating system. A function generator is used to create a sinusoidal $17.76 \mathrm{MHz}$ signal which is sent to a power amplifier. The signal is then sent through an impedance matching circuit and into the water cooled solenoid. For full details see $\mathrm{SI}$ page S12.

We observe an increase of thermolysin activity that is proportional to the applied RF power (and B field strength), without increasing the bulk temperature of the solution. The effective temperature of thermolysin can be correlated to different power inputs. We observe unique enzyme kinetics, consistent with a hot enzyme and cold substrate.

\section{Materials and Methods:}

\section{Magnetite $\mathrm{Fe}_{3} \underline{\mathrm{O}}_{4}$ Core synthesis procedure}

Magnetite cores were synthesized by thermal decomposition in diphenyl ether following a published method [25]. Briefly, in a $100 \mathrm{~mL} 3$ neck round bottom flask; $10 \mathrm{mmol}$ 1,2 hexadecane diol and 2 mmol iron (III) acytlacetonate was mixed in $20 \mathrm{~mL}$ of diphenyl ether. The solution was then purged and flushed with argon. Then $6 \mathrm{mmol}$ oleylamine (90\%) and $6 \mathrm{mmol}$ oleic acid was added via syringe. The solution was then heated to $200^{\circ} \mathrm{C}$ for 30 minutes to boil off impurities. Then it was heated to $265^{\circ} \mathrm{C}$ and refluxed for 1 hour then cooled to $30^{\circ} \mathrm{C}$, and transferred into scintillation vials for temporary storage. See SI S4 for complete details.

\section{Gold Coating Procedure}

The magnetite cores were coated using published procedure [26]. Briefly, $5 \mathrm{~mL}$ of the magnetite cores solution from above, without any rinsing or work up was added to a $100 \mathrm{~mL}, 2$ neck, round bottom flask. To that solution, $1.1 \mathrm{mmol}$ gold (III) acetate, $6 \mathrm{mmol}$ of 1,2-hexadecanediol, $0.75 \mathrm{mmol}$ oleic acid and $3 \mathrm{mmol}$ oleylamine was added in $15 \mathrm{~mL}$ diphenyl ether. This solution was stirred vigorously at $35^{\circ} \mathrm{C}$ while purging with argon for 20 minutes. Under argon and vigorous stirring the solution was then it was heated to $185^{\circ} \mathrm{C}$ and held at that temperature 1.5 hours. The particles were cleaned up by rinsing $3 x$ with 1:1 mixture of hexanes and ethanol. See SI S5 for complete details.

\section{Phase Transfer}

The phase transfer step proved to be very challenging and a novel two step procedure was used; first an initial exchange and phase transfer from oleylamine coating to 3-mercaptopropanoic acid (3-MPA). Then an exchange of 3-MPA for 11-mercaptoundecanoic acid (11-MUA) to increase solubility in water and biological relevant buffers. In a $20 \mathrm{~mL}$ scintillation vial, $2 \mathrm{~mL}$ of $17 \mathrm{mg} / \mathrm{mL}$ particle solution in heptanes was added with $10 \mathrm{~mL}$ of heptanes $5 \mathrm{~mL}$ of 3-MPA. This is then vortexed overnight. The particles were then precipitated and washed with $5 \mathrm{~mL}$ acetone 3x, until no 3-MPA smell could be detected. The particle pellet was then suspended in $1.5 \mathrm{~mL} 75 \mathrm{mM}$ tetramethylammonium hydroxide (TMAOH) solution to give a red solution [27].

To improve the stability of the particles in a wide range of solutions the 3-MPA ligands were further exchanged for longer 11-MUA ligands. To the $1.5 \mathrm{~mL}$ batch of phase transferred particles, $3.4 \mathrm{mg}$ of 11-MUA was added and the mixture was sonicated for 20 minutes to facilitate dissolution of the 11-MUA. The mixture was then vortexed for 4 hours at room temp. The particles were then centrifugally precipitated using acetone and rinsed $3 x$ with a 1:1 mixture of acetone to $75 \mathrm{mM}$ TMAOH. See SI S6 for complete details. 


\section{Covalent attachment to thermolysin (Conjugation)}

A novel conjugation procedure was developed to get around the incompatibility of the solubility of the nanoparticles and thermolysin, which is soluble in high ionic strength solutions. First $100 \mathrm{mg}$ of thermolysin

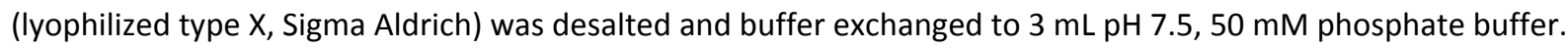
Then $10 \mathrm{mg}$ of lyophilized and thoroughly rinsed $\mathrm{Fe}_{3} \mathrm{O}_{4} @$ @u NP were dissolved in $3 \mathrm{~mL}$ fresh $50 \mathrm{mM} \mathrm{pH} 6.8$ phosphate buffer. Then $10 \mathrm{mg}$ of HATU was added to the nanoparticle solution and sonicated for 20 minutes. After sonication the HATU activated Au-NP solution was diluted with $6 \mathrm{~mL}$ of pH 6.8, $50 \mathrm{mM}$ phosphate buffer and added directly to the thermolysin pellet, and lightly vortexed for 3 hours at $4^{\circ} \mathrm{C}$. The conjugates were then precipitated via centrifuge, rinsed $2 x$ and then re-suspended in $10 \mathrm{~mL}$ of $\mathrm{pH} 7.5,50 \mathrm{mM}$ phosphate buffer. No enzymatic activity was detected in the second rinsing, indicating very little if any free thermolysin left in solution. Besides testing the activity of the magnetic conjugates, a SDS PAGE was used to confirm conjugation. See SI S6 for complete details.

\section{Thermolysin activity assay and bulk heating experiments}

The assay was based on the commercially available Pierce ${ }^{\mathrm{Tm}}$ Colorimetric Protease Assay Kit (catalog \# 23263) optimized for the specific enzyme conjugates and substrate. Aliquots (for $0,1,2,3$ minute time points) of 50 $\mu \mathrm{L}$ of $4 \mathrm{mg} / \mathrm{mL}$ succinylated casein in $50 \mathrm{mM} \mathrm{pH} 7.550 \mathrm{mM}$ phosphate buffer were pre-'heated' at $17.7^{\circ} \mathrm{C}$ (or different temperature for the temperature studies) in a thermocycler for 10 minutes along with a buffer blank. Then $5 \mu \mathrm{L}$ of thermolysin conjugates were added and the samples were heated for $0,1,2$ and 3 minute time points. To stop the reaction $10 \mu \mathrm{L}$ of $0.5 \mathrm{M}$ EDTA was added to chelate the catalytic zinc and structural calcium ion, denaturing thermolysin. Then after allowing the reaction to cool back down to room temperature for 5 minutes 25 $\mu \mathrm{L}$ of colorimetric reagent, TNBSA was added. The samples were then incubated at room temperature for 20 minutes, and using the pedestal on a NanoDrop uv-Vis spectrometer the absorbance was measured at $430 \mathrm{~nm}$ to monitor formation of the orange product that forms when primary amines react with TNBSA. The slope of the line was then used to calculate the velocity of the enzyme reaction. See SI S9 for complete details. The same activity assay was used to determine kinetic parameters of the reaction by varying the substrate concentration. See SI S15 for complete details

\section{Radiofrequency heating assays}

The exact same assay procedure was used for the RF heating experiments so that they were comparable. The fields were generated using a homemade water-cooled solenoid, with 14 turns and a length of $16 \mathrm{~cm}$. We measured the field strength with a hall effect probe and found it was $0.021 \mathrm{~T}$ in the center where the samples were placed. It was powered by a Philips PM5192 function generator to input a $17.76 \mathrm{MHz}$ sinusoidal signal into a IFI scx100 power amplifier. An impedance matching box was used to tune the reflected power to zero, new tunings were required for changes in frequency and applied power. See SI S12 for complete details. The bulk solution temperature was monitored with a Neoptix Nomad fiber optic temperature probe and then the conjugates were pre- heated in a thermocycler as described above to the same temperature, and the velocities of the two different heating methods were compared. Temperature measurements were made consistent by using a stand that holds the fiber optic probe in the same location for every sample. See SI S14 for complete details.

\section{Results and Discussion}

We investigated the activity of Thermolysin covalently conjugated to $6.1 \mathrm{~nm}$ diameter gold coated magnetite particles under RF irradiation. Thermolysin is a $34.6 \mathrm{kDa}$ metalloprotease from thermophilic bacteria Bacillus thermoproteolyticus [28-30]. It is active in the hydrolysis of peptide bonds with a preference for bonds between hydrophobic residues. Its activity is maximized at $\mathrm{pH} 8$ and increases with temperature until $70^{\circ} \mathrm{C}$ at which point it denatures. 
Magnetite particles were used because they are the superparamagnetic particles most frequently used in the literature for RF heating experiments. We gold coated the particles to stabilize the particles and allow for a robust covalent attachment of the conjugates through gold thiolate bonds, without negatively impacting the magnetic properties[31-33]. The optimal size magnetite cores were found for our system (17.7 MHz) to be $4 \mathrm{~nm}$ diameter [20]. We then coated the particles with the minimal amount of gold that would still allow for phase transferring and ligand exchange while maintaining solution stability. For complete details of the synthesis and phase transfer see SI page S3.

Thermolysin was attached to the gold coated iron-oxide particles through peptide bond formation using the carboxylic acid terminated ligands on the particles and the solvent accessible free lysine residues on thermolysin [34,35]. To significantly improve yield and decrease reaction time, a novel procedure was developed using HATU as a coupling reagent in buffer without any organic solvents (for details see SI page S5). This coupling procedure can be universally applied to enzymes, including those with very poor water solubility, a weak affinity for the ligand coating of the particle and high sensitivity to organic solvents like thermolysin.

The 17.76 MHz RF field was generated using a homemade water-cooled copper solenoid. A function generator was used to make a sinusoidal $17.76 \mathrm{MHz}$ signal that was amplified and sent to the coil. An oscilloscope was used to monitor the output of the amplifier and an impedance matching box was used to ensure that the applied power was not reflected back into the power amplifier, see figure 1 for an illustration of the heating system. The temperature of the solution was measured using a fiber optic temperature probe. The water cooling system was used because it maintained a much more constant sample temperature than a thermal insulator without attenuating the RF field, across a wide range of applied powers. For complete system details see SI page S12.

Preliminary experiments suggested higher power and higher frequency both increased the activity of enzyme/particle conjugates. The reported experiments were executed at $17.76 \mathrm{MHz}$ and $80 \mathrm{~W}$ incident power, as these were the highest values of incident power and frequency that we could accomplish with our equipment.

Figure 2, left panel, illustrates the increase in observed thermolysin/NP activity by colorimetric assay that occurs under these RF conditions. Overall, we observe that the thermolsyin/NP conjugate activity is increased by $129 \pm 8 \%$ under the $80 \mathrm{~W}, 17.76 \mathrm{MHz}$ RF irradiation when compared to a control reaction at the same solution temperature (as measured with a fiber optic (i.e.., metal-free) temperature probe). Figure 2, right panel shows the activity of each component of the thermolysin/NP conjugates (i.e., thermolsyin alone, NP alone) as well as the activity of thermolysin in the presence of unconjugated NP. Overall, we see a clear increase in activity of the enzyme relative to the controls. The measured maximum solution temperature in the $\mathrm{RF}$ fields was $17^{\circ} \mathrm{C}$, indicating that the increase in enzyme activity observed is a local effect, and does not extend to heating the bulk solution. The modest activity increase of free thermolysin under RF irradiation is likely due to local regions of heat generated by ions oscillating with the electric component of the RF field. We do not attribute any activation of thermolysin to adsorption on the particles surface because thermolysin is very hydrophobic and our attempts to conjugate by simple adsorption were very unsuccessful. Overall, we interpret this set of control experiments as validating that the observed increase in activity under RF is attributable primarily to local temperature increase around the nanoparticle that increases the effective operating temperature of covalently attached enzymes.

The data in Figure 2 were all collected at $17^{\circ} \mathrm{C}$ solution temperature, which is far from the optimal thermolysin temperature of $70^{\circ} \mathrm{C}$. By comparing the activity of thermolysin at various RF incident power values to the activity of thermolysin at various solution temperatures, we can propose effective 'local' temperature values for RF heated enzymes.

Figure 3 plots the activity of thermolysin as a function of solution temperature. We observe a linear relationship between temperature and enzyme rate $(\mathrm{k})$, from $10^{\circ} \mathrm{C}$ to $70^{\circ} \mathrm{C}$. At $80^{\circ} \mathrm{C}$, the enzyme rate decreases, which we attribute to partial thermal denaturation (Figure 3, black triangles). We observe a strikingly similar 
relationship for activity as a function of incident power (Figure 3, red circles). At $80 \mathrm{~W}$ the in $17^{\circ} \mathrm{C}$ solution temperature conjugates perform as if they are in $\sim 16^{\circ} \mathrm{C}$ warmer solution temperature.

We further investigated the enzyme kinetics of RF irradiated thermolysin/NP conjugates with concurrent controls identical in experimental setup except for the RF irradiation. Velocities were measured for various substrate concentrations. The results were analyzed with the Michaelis-Menten model of enzyme kinetics [36-39]. Figure 4 shows a double-reciprocal (i.e. Lineweaver-Burke plot, see SI page S15 for raw data). Analysis through equation 1 of this data produces the values for maximum enzyme velocity $\left(\mathrm{V}_{\mathrm{max}}\right)$, Michaelis constant $\left(\mathrm{K}_{\mathrm{M}}\right)$, and $\mathrm{K}_{\text {cat }}$. The two linear regressions were compared using GraphPad Prism 7.4 and with at a 95\% confidence interval the regression coefficients are statistically different.

$$
\frac{1}{v}=\frac{K_{M}}{V_{\max }[s]}+\frac{1}{V_{\max }}
$$

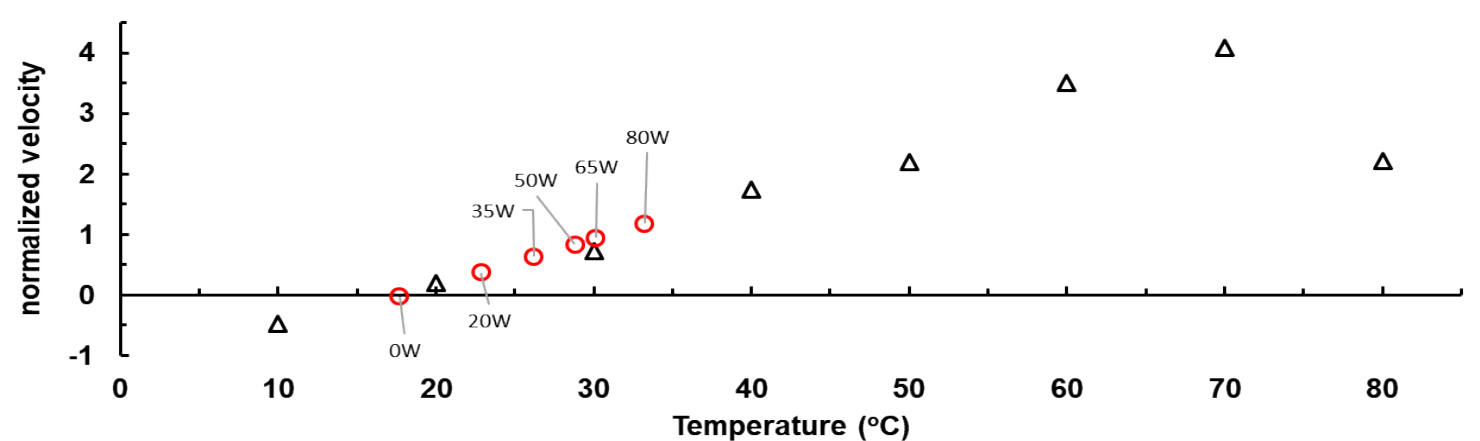

Figure 3. Plot of normalized activity of thermolysin as a function of temperature (black triangles) vs applied power (red circles). The zero point on the activity axis was set to the temperature of the solenoid without an RF field on.

These values are tabulated in Table 1. Under RF irradiation, the $\mathrm{V}_{\max }$ of thermolsyin/NP conjugates increase relative to the same sample in the absence of RF. We rationalize this by considering that transition states will be more stable (higher thermal energy results in lower activation energy barriers which speeds any reaction up [40]. More curiously, we observe a decrease in $K_{M}$ in RF fields. This may be understood through an examination of the thermolysin mechanism. Thermolysin most likely utilizes an induced fit mechanism of activity in which substrate molecules induces conformational changes in thermolysin that help it stabilize transition states [41]. Under typical heating conditions, global temperature increases the floppiness of the enzyme and substrate resulting in a smearing of states of the enzyme and substrate from the ideal state, but allows for more sampling of states.

\begin{tabular}{|l|l|l|}
\cline { 2 - 3 } \multicolumn{1}{c|}{} & Radiofrequency & Bulk Control \\
\hline $\mathrm{V}_{\max }(\mathrm{nmole} / \mathrm{min})$ & $0.169 \pm 0.059$ & $0.109 \pm 0.044$ \\
\hline $\mathrm{K}_{\mathrm{m}}(\mu \mathrm{M})$ & $48.0 \pm 6.0$ & $57.2 \pm 6.8$ \\
\hline $\mathrm{K}_{\text {cat }}\left(\mathrm{min}^{-1}\right)$ & $2.1 * 10^{-4}$ & $1.4^{*} 10^{-4}$ \\
\hline
\end{tabular}

Table 1. Summary of kinetics data for Michaelis Menten kinetics model.

The decrease in $\mathrm{K}_{M}$ (i.e., increase in stability of intermediate substrate enzyme complex) that occurs as a result of RF heating can be rationalized in terms of enzymatic mechanism. Thermolysin active site structure is modified by the substrate - an induced fit $[41,42]$. The substrate induced conformational changes in thermolysin structure stabilize the proteolytic transition state. Higher temperatures increase the rate of conformational sampling that the enzyme does in making an induced fit $[40,43]$. However, higher temperatures also increase the conformational sampling of the substrate, making induced fit less likely. In terms of the Michaelis-Menten model 
(scheme 1), higher temperatures increase both $k_{1}$ and $k_{-1}$. In bulk heating experiments $K_{M}$ increases with temperature because increased temperatures increase $k_{c a t}$ and influence enzyme substrate binding forward and backward rates equally.
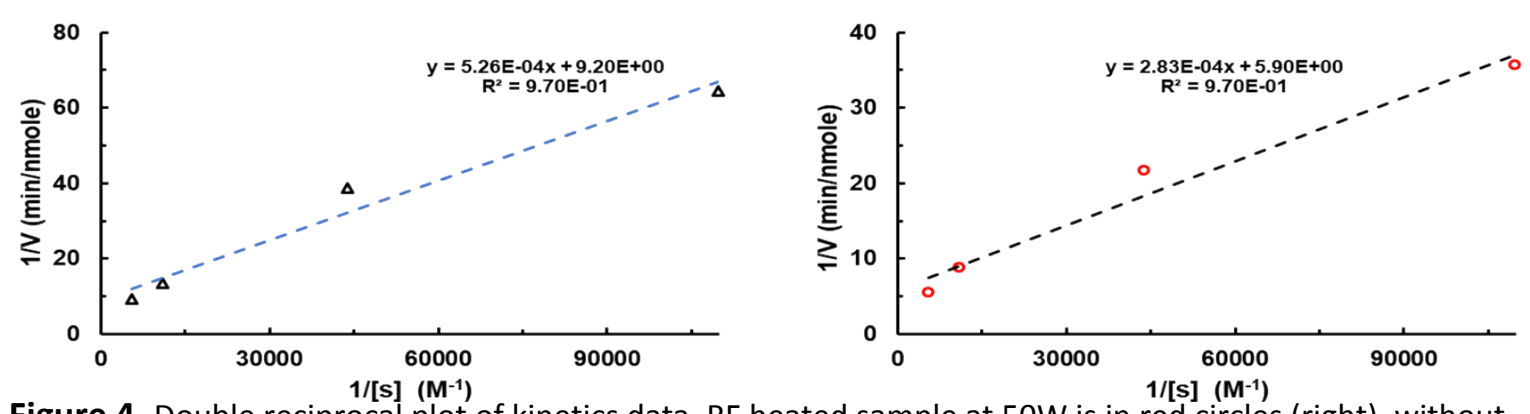

Figure 4. Double reciprocal plot of kinetics data, RF heated sample at $50 \mathrm{~W}$ is in red circles (right), without $\mathrm{RF}$ at the same temperature is the black triangles (left). From the intercept and slope we determined $\mathrm{K}_{\mathrm{m}}$ and $\mathrm{V}_{\max }$ and $\mathrm{k}_{\mathrm{cat}} \mathrm{using}$ the Michaelis-Menten model of enzyme kinetics.

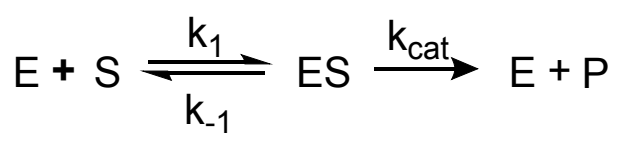

Scheme 1. Simplified enzymatic reaction for Michaelis Menten kinetics model. Its

In the radio-frequency fields, the enzyme is closer to the heat source than the substrate. Thus, the enzyme is sampling conformational space at a faster rate than the more rigid substrate. We suggest that this situation of 'hot enzyme, cold substrate' allows for a more rapid induced fit the enzyme is being heated results in additional floppiness of the enzyme, allowing for an easier induced fit of the substrate molecule. This results in higher $k_{1}$ because the substrate is docking with a floppier enzyme (allowing for best confirmation more easily) and then lower $k_{-1}$ because the substrate is held more firmly once its attached because of this same improvement in induced fit through enzyme floppiness [40].

\section{Conclusions}

We have successfully shown that thermolysin can be remotely activated in $17.76 \mathrm{MHz}$ RF fields when covalently attached to magnetic nanoparticles. Without raising the bulk solution temperature, under RF irradiation we observed enzyme activity as if the solution was $16 \pm 2{ }^{\circ} \mathrm{C}$ warmer, or an increase in enzymatic rate of $129 \pm 8 \%$. Further studies will be performed with higher field strengths to maximize the level of activation in RF fields. A preliminary investigation of the kinetics in and outside of the RF fields showed an increase in activity consistent with a hot enzyme interacting with a cold substrate. Our approach for remote control of enzyme activity seems to be universally applicable to any enzyme that has an induced fit mechanism of activity, but more investigation into the scope of this process is necessary.

\section{Acknowledgements}

This work was supported by NIH R01 GM112225.

\section{Notes and references}

1. Clark, D. P.; Pazdernik, N. J. Chapter E6 - Polymerase Chain Reaction. In Molecular Biology (Second Edition); Academic Press: Boston, 2013; pp e55-e61.

2. Sun, W. Chapter 4 - Nucleic Extraction and Amplification. In Molecular Diagnostics; Grody, C. W., Nakamura, R. M., Strom, C. M., Kiechle, F. L., Eds.; Academic Press: San Diego, 2010; pp 35-47. 
3. Butler, J. M. Chapter 4 - PCR Amplification: Capabilities and Cautions. In Advanced Topics in Forensic DNA Typing: Methodology; Academic Press: San Diego, 2012; pp 69-97.

4. Arya, M.; Shergill, I. S.; Williamson, M.; Gommersall, L.; Arya, N.; Patel, H. R. Basic Principles of Real-Time Quantitative PCR. Expert Rev. Mol. Diagn. 2005, 5, 209-219.

5. Najafov, A.; Hoxhaj, G. Chapter 1 - Introduction. In PCR Guru; Academic Press, 2017; pp 1-6.

6. van der Zee, J. Heating the Patient: A Promising Approach? Ann. Oncol. Off. J. Eur. Soc. Med. Oncol. 2002, $13,1173-1184$.

7. Hildebrandt, B.; Wust, P.; Ahlers, O.; Dieing, A.; Sreenivasa, G.; Kerner, T.; Felix, R.; Riess, H. The Cellular and Molecular Basis of Hyperthermia. Crit. Rev. Oncol. Hematol. 2002, 43, 33-56.

8. Wust, P.; Hildebrandt, B.; Sreenivasa, G.; Rau, B.; Gellermann, J.; Riess, H.; Felix, R.; Schlag, P. M. Hyperthermia in Combined Treatment of Cancer. Lancet Oncol. 2002, 3, 487-497.

9. Falk, M. H.; Issels, R. D. Hyperthermia in Oncology. Int. J. Hyperth. Off. J. Eur. Soc. Hyperthermic Oncol. North Am. Hyperth. Group 2001, 17, 1-18.

10. Glazer, E. S.; Curley, S. A. The Ongoing History of Thermal Therapy for Cancer. Surg. Oncol. Clin. N. Am. 2011, 20, 229-235.

11. Meselson, M.; Yuan, R. DNA Restriction Enzyme from E. Coli. Nature 1968, 217, 1110-1114.

12. Stephenson, F. H. Chapter 10 - Recombinant DNA. In Calculations for Molecular Biology and Biotechnology (Third Edition); Academic Press: Boston, 2016; pp 321-373.

13. Pelley, J. W. 18 - Recombinant DNA and Biotechnology. In Elsevier's Integrated Biochemistry; Mosby: Philadelphia, 2007; pp 159-167.

14. Hamad-Schifferli, K.; Schwartz, J. J.; Santos, A. T.; Zhang, S.; Jacobson, J. M. Remote Electronic Control of DNA Hybridization through Inductive Coupling to an Attached Metal Nanocrystal Antenna. Nature 2002, 415, 152-155.

15. Suzuki, M.; Aki, A.; Mizuki, T.; Maekawa, T.; Usami, R.; Morimoto, H. Encouragement of Enzyme Reaction Utilizing Heat Generation from Ferromagnetic Particles Subjected to an AC Magnetic Field. Plos One 2015, $10,11$.

16. Knecht, L. D.; Ali, N.; Wei, Y.; Hilt, J. Z.; Daunert, S. Nanoparticle-Mediated Remote Control of Enzymatic Activity. ACS Nano 2012, 6, 9079-9086.

17. Blankschien, M. D.; Pretzer, L. A.; Huschka, R.; Halas, N. J.; Gonzalez, R.; Wong, M. S. Light-Triggered Biocatalysis Using Thermophilic Enzyme-Gold Nanoparticle Complexes. ACS Nano 2013, 7, 654-663.

18. Dutz, S.; Hergt, R. Magnetic Nanoparticle Heating and Heat Transfer on a Microscale: Basic Principles, Realities and Physical Limitations of Hyperthermia for Tumour Therapy. Int. J. Hyperthermia 2013, 1-11.

19. Merabia, S.; Shenogin, S.; Joly, L.; Keblinski, P.; Barrat, J.-L. Heat Transfer from Nanoparticles: A Corresponding State Analysis. Proc. Natl. Acad. Sci. 2009, 106, 15113-15118.

20. Rosensweig, R. E. Heating Magnetic Fluid with Alternating Magnetic Field. J. Magn. Magn. Mater. 2002, 252, 370-374.

21. Adhikary, K.; Banerjee, M. A Thermofluid Analysis of the Magnetic Nanoparticles Enhanced Heating Effects in Tissues Embedded with Large Blood Vessel during Magnetic Fluid Hyperthermia. J. Nanoparticles 2016, 2016, e6309231.

22. Armijo, L. M.; Brandt, Y. I.; Mathew, D.; Yadav, S.; Maestas, S.; Rivera, A. C.; Cook, N. C.; Withers, N. J.; Smolyakov, G. A.; Adolphi, N. L.; et al. Iron Oxide Nanocrystals for Magnetic Hyperthermia Applications. Nanomaterials 2012, 2, 134-146.

23. Bakoglidis, K. D.; Simeonidis, K.; Sakellari, D.; Stefanou, G.; Angelakeris, M. Size-Dependent Mechanisms in AC Magnetic Hyperthermia Response of Iron-Oxide Nanoparticles. IEEE Trans. Magn. 2012, 48, 13201323.

24. Deatsch, A. E.; Evans, B. A. Heating Efficiency in Magnetic Nanoparticle Hyperthermia. J. Magn. Magn. Mater. 2014, 354, 163-172.

25. Sun, S.; Zeng, H.; Robinson, D. B.; Raoux, S.; Rice, P. M.; Wang, S. X.; Li, G. Monodisperse MFe2O4 (M = Fe, Co, Mn) Nanoparticles. J. Am. Chem. Soc. 2004, 126, 273-279. 
26. WangWang; Luo, J.; Fan, Q.; Suzuki, M.; Suzuki, I. S.; Engelhard, M. H.; Lin, Y.; Kim, N.; Wang, J. Q.; Zhong, C.-J. Monodispersed Core-Shell Fe3O4@Au Nanoparticles. J. Phys. Chem. B 2005, 109, 21593-21601.

27. Laaksonen, T.; Ahonen, P.; Johans, C.; Kontturi, K. Stability and Electrostatics of Mercaptoundecanoic Acid-Capped Gold Nanoparticles with Varying Counterion Size. ChemPhysChem 2006, 7, 2143-2149.

28. Dahlquist, F. W.; Long, J. W.; Bigbee, W. L. Role of Calcium in the Thermal Stability of Thermolysin. Biochemistry (Mosc.) 1976, 15, 1103-1111.

29. Matsubara, H. Observations on the Specificity of Thermolysin with Synthetic Peptides. Biochem. Biophys. Res. Commun. 1966, 24, 427-430.

30. Blumberg, S.; Holmquist, B.; Vallee, B. L. Reversible Inactivation and Superactivation by Covalent Modification of Thermolysin. Biochem. Biophys. Res. Commun. 1973, 51, 987-992.

31. Ackerson, C. J.; Jadzinsky, P. D.; Kornberg, R. D. Thiolate Ligands for Synthesis of Water-Soluble Gold Clusters. J. Am. Chem. Soc. 2005, 127, 6550-6551.

32. Robinson, I.; Tung, L. D.; Maenosono, S.; Wälti, C.; Thanh, N. T. K. Synthesis of Core-Shell Gold Coated Magnetic Nanoparticles and Their Interaction with Thiolated DNA. Nanoscale 2010, 2, 2624-2630.

33. WangWang; Luo, J.; Fan, Q.; Suzuki, M.; Suzuki, I. S.; Engelhard, M. H.; Lin, Y.; Kim, N.; Wang, J. Q.; Zhong, C.-J. Monodispersed Core-Shell Fe304@Au Nanoparticles. J. Phys. Chem. B 2005, 109, 21593-21601.

34. Ackerson, C. J.; Jadzinsky, P. D.; Sexton, J. Z.; Bushnell, D. A.; Kornberg, R. D. Synthesis and Bioconjugation of 2 and 3 Nm-Diameter Gold Nanoparticles. Bioconjug. Chem. 2010, 21, 214-218.

35. Heinecke, C.; Ackerson, C. Preparation of Gold Nanocluster Bioconjugates for Electron Microscopy. In Nanoimaging; Sousa, A. A., Kruhlak, M. J., Eds.; Methods in Molecular Biology; Humana Press, 2013; pp 293-311.

36. Cornish-Bowden, A. One Hundred Years of Michaelis-Menten Kinetics. Perspect. Sci. 2015, 4, 3-9.

37. Bhagavan, N. V.; Ha, C.-E. Chapter 6 - Enzymes and Enzyme Regulation. In Essentials of Medical Biochemistry; Academic Press: San Diego, 2011; pp 47-58.

38. Jia, H.; Zhu, G.; Wang, P. Catalytic Behaviors of Enzymes Attached to Nanoparticles: The Effect of Particle Mobility. Biotechnol. Bioeng. 2003, 84, 406-414.

39. Wong, J. F.; Simmons, C. A.; Young, E. W. K. Chapter 3 - Modeling and Measurement of Biomolecular Transport and Sensing in Microfluidic Cell Culture and Analysis Systems. In Modeling of Microscale Transport in Biological Processes; Becker, S. M., Ed.; Academic Press, 2017; pp 41-75.

40. Elias, M.; Wieczorek, G.; Rosenne, S.; Tawfik, D. S. The Universality of Enzymatic Rate-temperature Dependency. Trends Biochem. Sci. 2014, 39, 1-7.

41. Murray, C. W.; Baxter, C. A.; Frenkel, A. D. The Sensitivity of the Results of Molecular Docking to Induced Fit Effects: Application to Thrombin, Thermolysin and Neuraminidase. J. Comput. Aided Mol. Des. 1999, 13, 547-562.

42. Inouye, K.; Lee, S.-B.; Nambu, K.; Tonomura, B. Effects of PH, Temperature, and Alcohols on the Remarkable Activation of Thermolysin by Salts. J. Biochem. (Tokyo) 1997, 122, 358-364.

43. Arcus, V. L.; Prentice, E. J.; Hobbs, J. K.; Mulholland, A. J.; Van der Kamp, M. W.; Pudney, C. R.; Parker, E. J.; Schipper, L. A. On the Temperature Dependence of Enzyme-Catalyzed Rates. Biochemistry (Mosc.) 2016, 55, 1681-1688. 